vate amount of mathematics miglit be compulsory; for $\mathrm{B}$. Sc. one ancient and one modern language (unless these had been included in the first year's course), chemistry and wathematics; for M. B., in addition to the qualifying courses and examinations, which would cover all the minor courses of the University, a certain higher standard in either classics or mathematics should be required, as also two professorial courses, such as physiology and pathology, or a clinical subject. According to this scheme, a degree in arts or science would be open to men who might from their preliminary training be unable to think of preparing for such an ordeal as the London Matriculation. Take for an example a bright Board-school boy apprenticed in engineering or chemical works or engaged in an office. By attending evening classes he might pass a sufficient number of Society of Arts and Science and Art examinations to cover the first year's requirements. He might then, by attending an institution of the Birkbeck character for several years obtain certificates of the four minor courses. For the professorial courses be would probably have to give up his occupation for a year and attend college, though it is possible that a sutticiently advanced professorial course extending over two or three years might be arranged in the evenings. In this way a degree in science or in engineering might be obtained. Similarly an elementary schoolmaster who might have obtained certificates of his four minor courses in his training college might manage his professorial courses by either one year's attendance in the daytime or by two or three years' attendance on evenings and by Saturday instrucfon. A medical man who had studied in London and ebtained the conjoint diploma would require a year, which right be spent under eminent teachers of practical subjects, and if he had not already fulfilled the requirements as to general education of course he would have to do so now. A wedical student would probably prefer to take one professorial course in the early and one in the later portion of his career. The M.B. would thus be a decided advance on the mere qualification, but would be far less vexatious than the London M.B. The B.A. and B.Sc. degrees would be in educational value a nearer approach to Oxford and Cambridge honour degrees than to London ones. Law, music and even divinity degrees might doubtless be arranged for on a similar plan, which implies simply the recognition of existing teachers and institutions for the minor subjects and that of a few very eminent teachers as professors for the major subjects. Both sexes and all denominations and classes would thus be provided with the means of obtaining not merely degrees but real University education.

I am, Sirs, yours faithf ully,

Theodore MAXwell, M.D., B.A. Camb., B.Sc.

Woolwich, Jan. 23rd, 1893

\section{"THE SENSITIVENESS OF THE PERITONEUM."}

\section{To the Editors of THE LANCET.}

SIRS,-The evidence published in your last issue by Mr. Lawson Tait on the subject of the tenderness to touch of the healthy peritoneum was prefaced with an interpreta. tion by himself. May I be allowed, as Mr. Tait refers to my mame, to append, not any interpretation of the evidence, for that should lie with the individual reader, but a few remarks in analysis of the position of Mr. Tait's dictum in the matter?

When Mr. Tait first announced, in contradiction to a lecture recently delivered before the College of Physicians, that the healthy peritoneum is an extremely sensitive surface, he rested his statement upon the "agony to the patients" observed in the "few experiences" "when I have very rarely been obliged to put my fingers within the peritoneum of a patient not under an anæsthetic." At three weeks' later date his basis of observation (his opinion having in that time met with criticism) became enlarged to "the interpretation of the phenomena yielded to me by 3300 human peritoneal cavities." In his last letter it seems to him that on a matter "so simple" and "so cardinal our ignorance is even now profound," and he furnishes extracts from replies received to a circular letter issued to "all the surgeons of Great Britain and Ireland whose names are familiar in connexion with abdominal work." The extracts given are Erom nineteen letters, of which two have to be deducted as their writers express inability to furnish evidence. Of the seventeen observers, twelve record that their experierce is opposed to Mr. 'Tait's view and mention various facts they consider incompatible with that view. On the other hand, five record an opinion more or less in harmony with that of Mr. Tait. Of the extracts of these five, two are unfortunately extremely brief and confined to expression of opinion only. Of the remaining three, one speaks of "reflex sensibility" of the peritoneum, not stating. any belief or evidence of these being reflexes affecting consciousness; and one, although affirming sensitiveness, describes it as "not such as to require the use of an anæsthetic." The third, however, by Mr. Tait's assistant, does fully endorse Mr. Tait's own experience. Perhaps I may be allowed, as one of your readers interested in this question, to thank those gentlemen who have contributed their experience on the point. Especially I would do so as one whose time, mainly removed from clinical work, gives little opportunity for those precious glimpses of the physiology of the human nervous system that are so helpful for that analysis of mind it is one of the chief aims of science to perform. For students, like myself, removed from such opportunities the evidence reported from the clinicians in your last issue cannot but possess peculiar interest. Of this evidence the major part agrees with surgical statements previously published contra Mr. Tait's opinion, and reverses his assertion that the experiments on "animals" and the observations upon man do not agree.

I would not trespass further on your space were it not for the following point, which is material to Mr. Tait: In the preamble to his last communication his circular letter of inquiry is prefaced by the statement that it has been forwarded to "all the surgeons of Great Britain and Ireland whose names are familiar in connexion with abdominal work." Knowledge has come into my possession which places this statement by Mr. Tait in so curious a position that I must decline to pursue with him further any discussion whatsoever.-I am, Sirs, yours truly,

J zn. 24th, 1893.

\section{S. SHERRINGTON.}

\section{To the Editors of THE LANCET.}

SIns,--.The question of the sensibility of the peritoneum, introduced by Mr. Lawson Tait, is a very interesting one and there ought to be no difficulty in answering it. I am afraid a correct solution will never be arrived at by arguing or by writing to a large number of surgeons to get an expression of their opinions. General impressions are worthless if accuracy is to be obtained. Nothing but direct observation, whilst bearing in mind the special points to be observed, can be of any value. The conclusions arrived at after reading Mr. Tait's remarks and his collected opinions, are (1) that certain human peritoneums are very sensitive, others are not; (2) three observers of the same series of cases have very decided differences of opinion : here is the fallacy of general impressions. A number of cases carefully observed over a period of three or six months from several of our large hospitals should supply accurate data for arriving at some reliable conclusion. The following case has I think some bearing on the subject. On Jan. 9th, 1893, I operated on a case of strangulated femoral hernia with Mr. Clarke of Morley. The patient was a man aged sixty-seren, with bad bronchitis and a feeble, irregular pulse. I operated without any anæsthetic as $I$ felt it would be an additional risk to administer one. The patient winced a little with the skin incision, which was made by transfixion. The separation of the sac from the surrounding structures he said he could feel. I opened the sac, divided the stricture, reduced the gut and put my finger through the femoral ring into the peritoneal cavity. I asked the catient if it was painful. $\mathrm{He}$ said no. I then separated the sac as high up as possible, ligatured it near the femoral ring, and removed it. 'I'he patient said he could feel this, but "it was not so bad." After cleansing the parts I put in four or five sutures; at each prick of the needle the patient called out, and he said the stitching up was by far the most painful part of the operation. I am, Sirs, yours truly,

Leeds, Jan. 24th, 1893.

H. LiTtLew 00 .

\section{"INNERVATION OF THE PALATE."}

\section{To the Editors of THE LANCET.}

Sirs, - In answer to Dr. Leonard Kidd's criticism of my case of palatine paralysis in the series of cases of facial paralysis published in THe LaNCET of Jan. 7th, I have much 